\section{Estudo \\ CoDebate}

em Testão

Plamejamento
Revista Estudo \& Debate, Lajeado, v. 24, n. 3, 2017. ISSN 1983-036X

DOI: http://dx.doi.org/10.22410/issn.1983-036X.v24i3a2017.1382

\title{
O EFEITO DA ARRECADAÇÁO tributária E DO PIB NO ÍNDICE DE DESENVOLVIMENTO SOCIOECONÔMICO (IDESE) DOS MUNICÍPIOS DO ESTADO DO RIO GRANDE DO SUL
}

\author{
Ronaldo João Gaieski ${ }^{1}$, Tadeu Grando ${ }^{2}$, Vanessa de Quadros Martins ${ }^{3}$, Suelen Corrêa ${ }^{4}$, \\ Antônio Carlos Brunozi Junior ${ }^{5}$
}

\begin{abstract}
Resumo: $\mathrm{O}$ maior desafio para todo e qualquer governante é proporcionar o bem-estar da população, atendendo suas necessidades por meio da adequada gestão dos recursos públicos. Assim, este estudo teve por objetivo analisar se o nível de arrecadação e o PIB interferem no Índice de Desenvolvimento Socioeconômico nos municípios do estado do Rio Grande do Sul. A amostra foi constituída por 496 municípios gaúchos, com 2.480 observaçóes referentes ao período entre 2009 e 2013. Configurou-se, para a investigação do objetivo central do estudo, uma análise de regressão linear múltipla pelo método dos mínimos quadrados ordinários, com dados em painel com efeitos aleatórios. Os resultados do estudo demonstram que o nível de arrecadação e o PIB afetam positivamente o IDESE. Quanto à arrecadação, pode-se inferir que a cada $1 \%$ de crescimento no nível arrecadado tem-se $0,11 \%$ de melhora no IDESE. Para o PIB, a cada $1 \%$ de crescimento no PIB do município, ocorre uma melhoria de $0,06 \%$ no IDESE. Com isso, percebe-se que os municípios que mais arrecadam e que possuem maior riqueza proporcionam aos seus cidadãos uma maior qualidade de vida, por meio da oferta de melhores serviços públicos, beneficiando a população.
\end{abstract}

Palavras-chave: IDESE. Arrecadação. Municípios.

1 Pós-graduando em nível de Especialização MBA em Gestáo Financeira: Controladoria e Auditoria pela Fundação Getúlio Vargas - FGV. E-mail: ro_gaieski@hotmail.com

2 Doutorando em Ciências Contábeis pela Universidade do Vale do Rio dos Sinos - UNISINOS. Docente na Universidade de Passo Fundo - UPF. E-mail: mtadeugrando@bol.com.br

3 Doutoranda em Ciências Contábeis pela Universidade do Vale do Rio dos Sinos - UNISINOS. E-mail: vanessa_qm@yahoo.com.br

4 Mestre em Administração pela Faculdade Meridional - IMED. Docente na Universidade de Passo Fundo UPF. E-mail: sucorrea83@hotmail.com

5 Doutor em Ciências Contábeis pela Universidade do Vale do Rio dos Sinos - UNISINOS. Docente da Universidade Federal de Viçosa - Campus de Rio Paranaíba. E-mail: acbrunozi@yahoo.com.br 


\title{
THE EFFECT OF TAX REVENUE AND GDP IN THE SOCIO- ECONOMIC DEVELOPMENT INDICATOR (IDESE) OF THE CITIES OF THE STATE OF RIO GRANDE DO SUL
}

\begin{abstract}
The biggest challenge for every government is to provide welfare to the population, Meeting their needs through the management of public resources. This study aims to analyze if the level of tax revenue interferes and GDP in the Socio-economic Development Indicator (IDESE) of the cities in the state of Rio Grande do Sul. The sample comprised 496 cities, with 2480 observations concerning the period between 2009 and 2013. For the investigation of the main objective of this study, it was methodologically configured a multiple linear regression through the method of ordinary least squares, with panel data with random effects. General results permitted to identify that the level of tax revenue and the GDP positively affect the IDESE. Regarding the tax revenue, it is possible to infer that for every $1 \%$ of increase, there is $0.11 \%$ of growth in the IDESE. Concerning the cities' GDP, for every $1 \%$ of increase, there is a growth of $0.06 \%$ in the IDESE. Therefore, it is noticeable that the cities with the biggest tax revenues and greatest wealth are able to provide their citizens a better quality of life by allocating this wealth to services that benefit the population.
\end{abstract}

Keywords: IDESE. Tax revenue. Cities.

\section{INTRODUÇÁO}

O maior desafio para todo e qualquer governante é o de proporcionar o bem-estar da população, atendendo suas necessidades por meio dos recursos arrecadados que lhe estáo disponíveis. Essa é a principal função do Estado.

Essa função é cumprida por meio da prestação de serviços públicos. De acordo com Kohama (2014), serviços públicos são todos aqueles prestados pelo Estado, ou delegados por concessão ou permissão perante condiçôes impostas e fixadas por ele, visando à satisfação de necessidades da comunidade.

A capacidade de atender as demandas da população limita-se aos recursos disponíveis à Administração Pública. Para Silva (2011), as finanças públicas envolvem toda a ação do Estado, para atendimento das necessidades coletivas. Na esfera municipal, cabe aos governantes o recolhimento das receitas e, após, as decisóes para destinação das mesmas, respeitando a legislação vigente. As receitas municipais provêm da própria arrecadação tributária e também das transferências de recursos por parte dos Governos Estadual e Federal.

Os municípios destacam-se por ser o órgão público mais próximo e de maior contato com os cidadãos, tendo assim maior poder de ação no tocante às demandas dos habitantes. De acordo com Keinert (2001), para 'medir' o desempenho e os resultados dos programas ou atividades públicas realizadas pelos gestores municipais, são utilizados os indicadores sociais.

No Brasil, são utilizados alguns indicadores sociais e econômicos capazes de mensurar o nível de desenvolvimento e qualidade de vida que os municípios oferecem à sua população. Dentre esses indicadores, no estado do Rio Grande do Sul (RS), podem-se destacar o Índice de Desenvolvimento Humano Municipal (IDH-M), o Índice de Desenvolvimento Socioeconômico (IDESE) e o Produto Interno Bruto (PIB). Para efeitos deste estudo, serão utilizados os indicadores IDESE e PIB. 
Nesse contexto, e tendo em vista que a arrecadação municipal, embora determinada por legislação específica, possui significantes diferenças de um município para outro, pois depende do nível de desenvolvimento econômico (comércio, indústria, nível de renda etc.) de cada município e, ainda, levando-se em conta que o nível de eficiência do gasto público é heterogêneo entre as prefeituras, determina-se a seguinte questão de pesquisa: Qual o efeito da arrecadação tributária e do PIB no Índice de Desenvolvimento Socioeconômico nos municípios do estado do Rio Grande do Sul? Objetivamente, o estudo visa determinar se o nível de arrecadação tributária e do PIB interferem no Índice de Desenvolvimento Socioeconômico dos municípios do estado do Rio Grande do Sul.

O presente estudo justifica-se pela necessidade de mensurar a eficiência na arrecadação tributária pelos municípios gaúchos e no emprego dos recursos captados em prol da qualidade de vida de seus moradores. Justifica-se ainda por se tratar de um tema relevante, com poucos estudos e análises pautadas a ele, não sendo encontrado nenhum trabalho que mensure a relação proposta nessa pesquisa no estado do RS. A contribuição principal do estudo está em demonstrar como a arrecadação de tributos e os níveis de riqueza municipal impactam nos índices de desenvolvimento humano.

A seguir, no capítulo 2, apresentam-se os conceitos que serviram de base para o desenvolvimento do estudo. No capítulo 3 são apresentados os procedimentos metodológicos utilizados para responder a questáo de pesquisa, seguindo-se para os resultados e suas discussóes no capítulo 4. Por fim, a título de considerações finais, discutem-se as principais constataçôes desta pesquisa, bem como suas limitaçôes e sugestôes para futuros estudos no capítulo 5.

\section{REVISÃO DA LITERATURA}

\subsection{Atividade Financeira do Estado}

Para Silva (2011), a atividade financeira do estado é a maneira que este usa para atender as necessidades públicas. Ainda segundo Silva (2011), a gestão financeira da Fazenda Pública deve ser organizada de forma em que se consiga arrecadar o máximo de recursos financeiros possíveis, para que o Governo possa cumprir com sua política maior, que é proporcionar o bem-estar à comunidade.

\subsubsection{Orçamento e Planejamento Público}

De acordo com Silva (2011), o planejamento, por ser a primeira etapa do processo de gestão, é feito anteriormente à realização das ações do governo. É entendido como um processo racional, onde se definem os objetivos e/ou metas a atingir e os meios que serão usados para alcançá-los, devendo expressar, ainda, a responsabilidade do governo para com a sociedade.

O processo de planejamento e a definição do orçamento público devem obedecer à Constituição Federal e ambos têm início na elaboraçáo do Plano Plurianual (SLOMSKI, 2003). Com base nesse Plano Plurianual, é posteriormente elaborada a Lei de Diretrizes Orçamentárias (LDO) e também a Lei do Orçamento Anual (LOA), priorizando assim as 
necessidades de curto prazo. São elaborados, também, planos de longo prazo, abordando situaçóes desejadas para os próximos dez ou quinze anos, partindo da análise da situação atual (SLOMSKI, 2003).

O Orçamento Público é uma lei de iniciativa do Poder Executivo que determina as políticas públicas para o exercício de referência. O Orçamento Público tem por base o Plano Plurianual e a LDO, já aprovada pelo Poder Legislativo. Trata, basicamente, da expectativa de receita e fixação da despesa (SLOMSKI, 2003).

A adoção de um Sistema de Planejamento Integrado, segundo Kohama (2014), baseiase no objetivo de determinar as açóes a serem realizadas pelo poder público, escolhendo as prioridades e compatibilizando-as com os meios disponíveis para colocá-las em execução. Percebe-se que os governos devem utilizar a ação planejada e transparente na gestão fiscal.

O orçamento é dividido em Receitas e Despesas, tanto no aspecto jurídico quanto no contábil. As previsōes de despesa pública contidas no Orçamento destacam um caráter limitativo, inibindo e proibindo a administração de efetuar gastos além da receita. Já, ao estimar a receita pública, o legislador não limita as faculdades de arrecadação do poder público, apenas tem por objetivo fundamentar o montante dos gastos (SILVA, 2011).

\subsubsection{Receita e Despesa Pública}

Todo e qualquer recolhimento feito aos cofres públicos, incluindo a variação ativa, proveniente do direito a receber no momento da ocorrência do fato gerador consiste na Receita Pública (KOHAMA, 2014). O recebimento ocorre através de numerário ou outros bens representativos de valores - que o Governo tem direito de arrecadar conforme leis, contratos ou quaisquer outros títulos que derivem direitos a favor do Estado -, quer seja oriundo de alguma finalidade específica, cuja arrecadação lhe pertença, ou caso figure apenas como depositário dos valores que não lhe pertencem.

Ainda para Kohama (2014), o reconhecimento da receita deverá ser feito sob os enfoques patrimonial e orçamentário. Em se tratando do enfoque patrimonial, deve-se utilizar a variaçáo ativa ocorrida no patrimônio, em contrapartida do direito no momento da ocorrência do fato gerador, de acordo com o regime de competência. Já o enfoque orçamentário considera a receita no momento efetivo do recolhimento efetuado aos cofres públicos, em concordância com o regime de caixa.

A Receita Pública divide-se em receita orçamentária e extraorçamentária. A receita orçamentária, regida pela Lei Federal no 4.320/64, é aquela que pertence de fato à entidade e se classifica economicamente em receitas correntes e receitas de capital. São receitas correntes as receitas tributárias, de contribuiçôes, patrimonial, agropecuária, industrial, de serviço e outras, além das originárias de recursos financeiros recebidos de outras pessoas de direito público ou privado, quando destinadas a atender a despesas classificáveis como despesas correntes.

Ainda segundo a lei, as receitas de capital são aquelas provenientes da realizaçáo de recursos financeiros oriundos de constituição de dívidas, da conversão, em espécie, de bens e direitos; os recursos recebidos de outras pessoas de direito público ou privado, destinados a atender as despesas classificáveis em Despesas de Capital e, ainda, o superávit do Orçamento 
Corrente. O superávit do Orçamento Corrente resulta no balanceamento dos totais das receitas e despesas correntes, apurado na demonstração da receita e despesa, segundo as categorias econômicas.

Por sua vez, a receita extraorçamentária é representada no balanço patrimonial como passivo financeiro, como recursos de terceiros que apenas transitam pelos cofres públicos, não pertencendo de fato ao Estado (SLOMSKI, 2003). A receita extraorçamentária compreende os recolhimentos feitos que constituam compromissos exigíveis, cujo pagamento independe de autorização orçamentária; o Estado arrecada valores que, em princípio, não lhe pertencem, como por exemplo: cauçôes, fianças, consignaçôes e outras (KOHAMA, 2014).

Por outro lado, caracteriza-se como Despesa Pública todos os desembolsos efetuados pelo Estado a fim de atender as necessidades da população (SILVA, 2011). Ainda segundo o autor, a despesa pode ser entendida em dois aspectos; no aspecto geral, como o conjunto de dispêndios do Estado no atendimento de suas 'obrigações' para com a população e; no aspecto específico, como a aplicação de determinado valor, pela autoridade ou pelo agente público, dentro de uma autorização legislativa.

A Despesa Pública também se classifica em orçamentária e extraorçamentária. A despesa orçamentária é aquela que depende de autorização legislativa, ou seja, não é permitida sua ocorrência sem crédito orçamentário correspondente (KOHAMA, 2014). Já a despesa extraorçamentária compreende aquela que independe de autorização legislativa - são as saídas do passivo financeiro provenientes de receitas extraorçamentárias, correspondendo ao pagamento de valores recebidos como cauçóes, depósitos, consignaçóes e outros. Kohama (2014) ressalta ainda que os resgates relativos às operaçóes de crédito por antecipação de receita (empréstimos e financiamentos de curto prazo) também são considerados extraorçamentários, pois constituem respectivamente, saídas compensatórias de entradas no ativo e passivo financeiro.

Ao final do exercício, as despesas empenhadas e não pagas até dia 31 de dezembro constituiráo os Restos a Pagar, ou seja, uma vez empenhada, a despesa pertence ao exercício, onerando as dotaçóes orçamentárias do mesmo (KOHAMA, 2014).

\subsection{Arrecadaçáo Municipal}

A receita municipal é constituída pela própria arrecadação tributária e também das transferências constitucionais de recursos provenientes do Governo Estadual e Federal. O Sistema Tributário Nacional disciplina a arrecadação e distribuição de receitas à União, aos Estados, ao Distrito Federal e aos Municípios.

Os tributos são de competência da Uniáo, dos Estados e Municípios, conforme distribuição estabelecida pela Constituição Federal (CF) em vigor. Para Oliveira et al. (2014, p. 5), os tributos são classificados em:

- Impostos: decorrem de situaçáo geradora, independente de qualquer contraprestaçáo do estado em favor do contribuinte;

- Taxas: estão vinculadas à utilização efetiva ou potencial por parte do contribuinte, de serviços públicos específicos e divisíveis; 
- Contribuiçóes de Melhorias: cobradas quando do benefício trazido aos contribuintes por obras públicas.

Ainda para os autores Oliveira et al. (2014), as taxas e contribuiçóes de melhoria geram um baixo montante arrecadado e, consequentemente, causam pouco impacto ao contribuinte. Os impostos, por sua vez, são o instrumento que o governo dispóe para recolher recursos a fim de gerir a Administração Pública e investir em obras públicas.

Os tributos arrecadados pela União e pelos Estados têm parte dos valores repassados aos municípios, enquanto estes últimos entes ficam com todo o valor dos impostos que the compete cobrança. Essas transferências estão determinadas pela Constituição Federal (Art. 158 e 159) e Código Tributário Nacional (CTN), ou ainda, por Emendas Constitucionais ou Atos e Leis Complementares.

De acordo com o texto da Constituição Federal, Seção VI, da arrecadação da União com o Imposto de Renda (IR) e Imposto sobre Produtos Industrializados (IPI), parte desses retornam aos municípios através do Fundo de Participação dos Municípios (FPM). Atualmente, o percentual de retorno é de 22, 5\%, repassados decendialmente aos municípios com base nos valores apurados no decêndio anterior pelo Sistema Integrado de Administração Financeira (SIAFI), mais 1\%, que é acumulado por doze meses e repassado no primeiro decêndio de dezembro do ano em curso (totalizando um repasse de 23,5\%).

O repasse do FPM obedece ao seguinte rateio: 10\% destinado às Capitais, 86,4\% destinados aos Municípios do Interior e 3,6\% são enviados aos Municípios da Reserva (que são aqueles com mais de 142.633 habitantes). Os municípios da Reserva recebem o valor referente ao percentual de municípios do Interior acrescido do percentual da Reserva por possuírem população mais elevada. Sobre o valor equivalente ao percentual de retorno de 22,5\%, desconta-se um percentual de 20\% referente ao Fundo de Manutençáo e Desenvolvimento da Educação Básica e de Valorização dos Profissionais da Educação (FUNDEB) e 1\% referente ao Programa de Formação do Patrimônio do Servidor Público (PASEP), já sobre o $1 \%$ de repasse anual, incide desconto referente ao PASEP apenas.

A União ainda repassa aos municípios $50 \%$ do produto da arrecadação do Imposto sobre Propriedade Territorial Rural (ITR), na proporcionalidade de imóveis situados no território de cada município.

De acordo com a seção VI da Constituição Federal, que trata da arrecadação Estadual, $25 \%$ do Imposto sobre Circulação de Mercadorias e Serviços (ICMS) recolhido é repassado de volta aos municípios. O índice de participação dos municípios é apurado pela Secretaria da Fazenda de acordo com critérios definidos em lei. Com relação ao Imposto sobre Propriedade de Veículo Automotor (IPVA), o município recebe 50\% do valor arrecadado de todos os veículos emplacados no município.

Em síntese, os Municípios recebem do governo Estadual e Federal parte do valor arrecadado com impostos de competência destes, na proporcionalidade de contribuiçáo do referido município. Além desses repasses, os municípios usufruem dos Impostos, Taxas e Contribuiçôes de Melhoria que lhe competem arrecadação própria. 


\subsection{Indicadores e Desenvolvimento Social}

Foi-se o tempo em que indicadores sociais eram utilizados apenas por estatísticos e matemáticos. A referência aos indicadores faz-se necessária na hora de medir desempenho e resultados de qualquer programa ou atividade pública efetivada. Cada vez mais, o público qualificado e os analistas querem saber quais os resultados alcançados na gestão sob múltiplos enfoques e abordagens, não somente realizando comparaçóes com dados de períodos passados (KEINERT, 2001).

Um indicador social é uma medida, em geral quantitativa, dotada de significado social significante, usada para substituir, quantificar ou operacionalizar um conceito social abstrato, de interesse teórico (para pesquisa acadêmica) ou programático (para formulação de políticas). É um meio metodológico que informa algo sobre um aspecto da realidade social ou sobre mudanças que estão se processando na mesma (CARLEY, 1985).

Keinert (2001) defende ainda que estes indicadores, além de medir a eficiência ou não das políticas públicas, servem também como método para avaliar os avanços ou retrocessos nas condiçóes de vida da população - definiçâo esta dada ao termo desenvolvimento social.

Os indicadores de desenvolvimento social estão atrelados aos indicadores econômicos, na medida em que uma condição de vida melhor pode ser oferecida à população através do acesso aos bens e serviços. O desenvolvimento social deve ser um dos principais objetivos do Estado (FONSECA; FAGNANI, 2013).

Dentre os principais indicadores sociais destacam-se o IDH e o IDESE. Nesse estudo, optou-se pela utilização do IDESE por ser um indicador anual, diferentemente do primeiro, que é divulgado a cada dez anos. Dentre os indicadores econômicos, temos como principal e mais empregado o PIB e, por isso, optou-se pela utilização do mesmo nesse estudo.

\subsubsection{IDESE}

O IDESE, de acordo com definição encontrada no site da FEE, é um indicadorsíntese que tem o propósito de mensurar o nível de desenvolvimento dos municípios do estado do Rio Grande do Sul. O objetivo de sua divulgação é avaliar e acompanhar a evoluçáo dos indicadores socioeconômicos dos municípios do Estado, bem como fornecer informaçôes para o desenho de políticas públicas específicas, de acordo com as necessidades municipais. Ainda conforme o texto do site, o IDESE é composto por 12 indicadores, divididos em três blocos: Educação, Renda e Saúde.

O Bloco Educação utiliza cinco indicadores que se dividem em quatro sub-blocos, de acordo com faixas etárias. O índice final do Bloco Educação é a média aritmética dos índices desses sub-blocos. 
Quadro1 - Bloco Educação

\begin{tabular}{|l|l|l|l|}
\hline $\begin{array}{c}\text { Populaçáo entre } \\
\text { 4 e 5 anos }\end{array}$ & \multicolumn{1}{|c|}{$\begin{array}{c}\text { Populaçáo entre } \\
\mathbf{6} \text { e 14 anos }\end{array}$} & $\begin{array}{c}\text { Populaçáo entre } \\
\mathbf{1 5} \text { e } \mathbf{1 7} \text { anos }\end{array}$ & \multicolumn{1}{c|}{$\begin{array}{c}\text { Populaçáo de } \\
\mathbf{1 8} \text { anos ou mais }\end{array}$} \\
\hline $\begin{array}{l}>\text { Taxa de matrícula } \\
\text { na pré- escola. }\end{array}$ & $\begin{array}{l}>\text { Nota da Prova Brasil do 50 } \\
\text { ano do ensino fundamental; } \\
\text { > Nota da prova Brasil do 9o } \\
\text { ano do ensino fundamental. }\end{array}$ & $\begin{array}{l}>\text { Taxa de matrícula } \\
\text { no ensino médio. }\end{array}$ & $\begin{array}{l}\text { Percentual da } \\
\text { populaçáo adulta } \\
\text { com, pelo menos, o } \\
\text { ensino fundamental } \\
\text { completo. }\end{array}$ \\
\hline
\end{tabular}

Fonte: Site FEE, 2016.

O Bloco Renda é composto por dois sub-blocos que analisam a renda por duas óticas distintas: apropriação de renda e geração de renda. O índice final do Bloco Renda é a média aritmética de seus sub-blocos.

Quadro 2-Bloco Renda

\begin{tabular}{|c|c|}
\hline \multicolumn{1}{|c|}{ Renda apropriada } & Renda gerada \\
\hline$>$ Renda domiciliar per capita média. & > Produto Interno Bruto (PIB) per capita. \\
\hline
\end{tabular}

Fonte: Site FEE, 2016.

Por fim, o Bloco Saúde utiliza cinco indicadores que são divididos em três subblocos. O índice final do Bloco Saúde é a média aritmética dos índices desses sub-blocos.

Quadro 3-Bloco Saúde

\begin{tabular}{|c|c|c|}
\hline Saúde materno-infantil & Condiçóes gerais de saúde & Longevidade \\
\hline $\begin{array}{l}\text { > Taxa de mortalidade de menores de } \\
\text { cinco anos (TMM5); } \\
\text { > Número de consultas pré-natais por } \\
\text { nascidos vivos. }\end{array}$ & $\begin{array}{l}\text { > Taxa de mortalidade por } \\
\text { causas evitáveis; } \\
>\text { Proporçáo de óbitos por } \\
\text { causas mal definidas. }\end{array}$ & 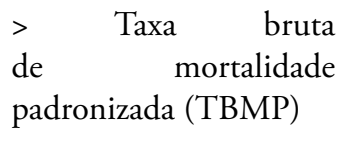 \\
\hline
\end{tabular}

Fonte: Site FEE, 2016.

\subsubsection{Produto Interno Bruto Municipal}

O Produto Interno Bruto (PIB) mensura o que foi produzido num país em determinado período de tempo. O PIB mede o esforço produtivo de um país no período em análise e, com isso, indica a riqueza desse país pela capacidade que o mesmo tem de gerar emprego e renda. É um dos indicadores mais utilizados na macroeconomia (FEIJÓ, 2011).

Para Kasznar (2013), o PIB fornece uma medida de valor econômico-financeiro de todos os bens e serviços produzidos num dado país, em um ano específico, logo dá a ideia de poder econômico. Quanto maior o PIB, tanto maior é em tese o poder econômico agregado do país, estado ou município analisado. 
No caso do PIB Municipal, as informaçôes são geradas por município, de forma padronizada, e permitem a compreensão de uma dimensão produtiva localizada. Assim sendo, é possível realizar análises entre municípios com dados comparáveis para a classificação de atividades e produtos.

Para Kasznar (2013) desde a Constituição de 1988, ampliaram-se as demandas por informaçóes econômicas municipais bem detalhadas, padronizadas e que admitem comparabilidade. Os resultados numéricos desse projeto de mediçấo do PIB dos 5.567 municípios têm sido amplamente usados para apoiar a análise da economia municipal brasileira.

O PIB demonstra quanto e como ocorre o crescimento da economia, não sendo capaz, no entanto, de refletir a qualidade desse crescimento. Isso porque enquanto a economia cresce, pode haver acumulaçáo de renda entre poucos, fazendo aumentar assim a pobreza (FEIJÓ, 2011).

Já o crescimento econômico está relacionado a mudanças de caráter quantitativo, significando aumento em dimensão, volume e/ou quantidade (SIEDENBERG, 2006). No entanto, se esse crescimento resultar em melhoria dos indicadores sociais, entáo pode ser tratado como desenvolvimento. Nestes termos, o desenvolvimento é um processo de mudanças tanto econômicas quanto sociais que ocorrem em determinada região.

Para Pavarina (2003), o desenvolvimento ou crescimento econômico é compreendido como o processo de expansão de renda da populaçáo de determinada regiáo desde que essa expansão também resulte na melhora de qualidade de vida das pessoas.

\subsubsection{A Arrecadaçáo Municipal e o PIB versus Indicadores de Desenvolvimento Social}

Gallo et al. (2012) analisaram se a distribuição da arrecadação do ICMS - Imposto sobre a Circulação de Mercadorias e Serviços - no Estado do Pará tem contribuído para a melhoria da qualidade de vida nos municípios paraenses, de acordo com o IDH-M. Os resultados demonstraram que maiores níveis de arrecadação de ICMS não influenciaram de maneira significativa o comportamento do IDH-M nos municípios analisados. Nesse sentido, conforme os autores, o aumento de arrecadação pelo ICMS não possibilitou um aumento na qualidade de vida das pessoas.

Avelar, Garcia e Santos (2012) verificaram como o crescimento econômico brasileiro de 2000 a 2010 interferiu na melhora nos índices de qualidade de vida. Para os autores, é irrefutável a relação existente entre crescimento econômico e desenvolvimento social, principalmente quando se observam os dados brasileiros de PIB, Coeficiente de Gini, $\mathrm{IDH}$, expectativa de vida e pobreza. Esses indicadores alcançaram significativa melhora no período analisado, quando o crescimento do PIB se mostrou marcante: de 644 bilhóes para 2 trilhōes de dólares, aproximadamente.

Ainda segundo o mesmo estudo, o crescimento econômico foi acompanhado de uma significativa elevação do PIB per capita, que indica uma melhora no poder aquisitivo da população brasileira. Outro indicador social relevante que obteve bons resultados foi o IDH, que passou de 0,665 para 0,715 em igual período, evidenciando a melhoria das condiçóes de vida em termos de rendimentos, expectativa de vida e educação. 
Silva et al. (2013) avaliaram as políticas públicas tributárias dos municípios de Minas Gerais em 2010, com base nos recursos provenientes da receita tributária e orçamentária utilizados em políticas públicas, juntamente com o desempenho da gestão fiscal, analisando a influência destes fatores no Índice Firjan de Desenvolvimento dos municípios mineiros. Foi constatado que os municípios que apresentaram maior volume de receita tributária e orçamentária, juntamente com uma boa gestão fiscal, apresentaram também um bom índice de desenvolvimento social.

Almeida (2014) teve objetivo estudar a eficiência da tributação no Brasil, por meio da relação com o Índice de Desenvolvimento Humano (IDH), comparando-o a 30 países selecionados. Constatou-se que a carga tributária brasileira é alta, e apresenta retornos à sociedade em forma de bem-estar pouco significante. E que vários países apresentam carga tributária menor que a do Brasil, mas possuem retornos à sociedade superiores. Concluiu-se que pela ineficiência do Brasil, são necessários ajustes no sistema tributário nacional bem como na gestão pública sobre esta arrecadação.

Fernandes (2017) teve como objetivo analisar os efeitos dos diferentes desempenhos tributários nos índices de desenvolvimentos econômicos e sociais em municípios mineiros. Os resultados indicaram que os municípios com alto desempenho tributário tendem a melhorar os seus índices de desenvolvimento econômico e social. O montante tributário arrecadado e a satisfatória gestão destes recursos podem propiciar o oferecimento de serviços públicos como geração de emprego e renda, educação e saúde com maior qualidade.

\section{PROCEDIMENTOS METODOLÓGICOS}

\subsection{Delineamento, Populaçáo e Amostra}

Trata-se de uma pesquisa descritiva e documental, com abordagem quantitativa do problema. A população desta pesquisa consiste nos 497 municípios do Rio Grande do Sul, segundo o site da Fundação de Economia e Estatística (FEE) em consulta no ano de 2016. A amostra compóe-se por 496 municípios gaúchos, ficando de fora apenas o município de Pinto Bandeira, que foi emancipado em 2013 e, por isso, não possui dados referentes ao período de 2009 a 2012.

O estudo considerou os dados do período entre 2009 e 2013, totalizando 2.480 observaçóes analisadas. Justifica-se a não utilização dos anos 2014 e 2015 , uma vez que os dados referentes a esse biênio não foram inteiramente publicados.

\subsection{Plano de coleta e tratamento de dados}

As informaçóes usadas na pesquisa foram coletadas - via internet - no site da FEE, bem como no site do Tribunal de Contas do Estado do RS (TCE-RS). Os dados foram coletados nos meses de setembro e outubro de 2016.

A variável arrecadação municipal foi encontrada no site do TCE-RS, já as demais variáveis que são população, IDESE e PIB foram encontradas no site da FEE. Na Figura 1, pode-se visualizar como foi realizada a coleta dos dados: 
Figura 1 - Fluxograma de procedimento de coleta de dados

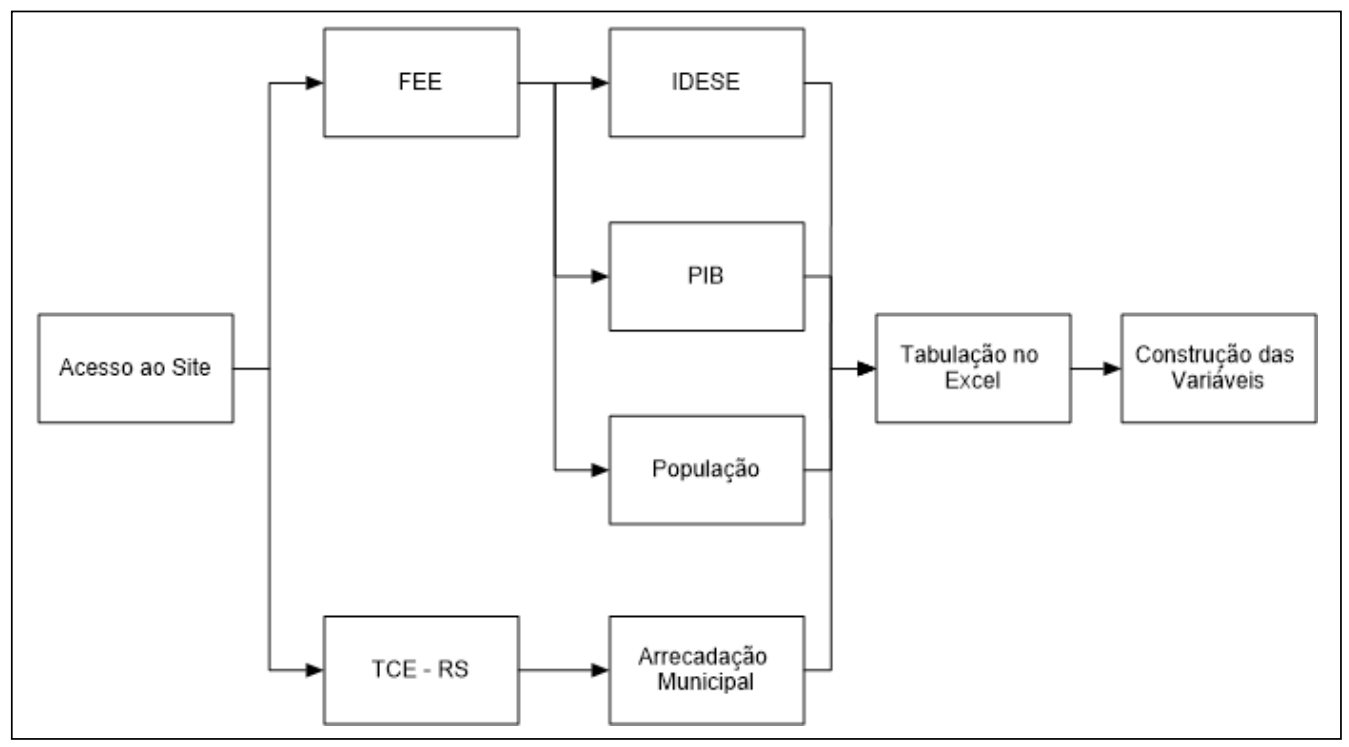

Fonte: Elaboração própria (2016).

Posteriormente à coleta dos dados, realizou-se a tabulação dos dados no Excel para a construção das variáveis.

\subsection{Definiçáo operacional das variáveis}

O IDESE constitui a variável dependente do estudo, já que sofre influência do nível de arrecadaçáo municipal. Este indicador é mensurado em uma escala de 0 a 1 , sendo que quanto mais próximo a 1, melhor é o índice municipal obtido. Para o cálculo do IDESE são levados em conta os fatores saúde, educação e renda.

As variáveis independentes da pesquisa são a arrecadação municipal - que será utilizada na forma de arrecadaçáo per capita - e o PIB. A arrecadaçáo per capita será calculada dividindo-se o valor total arrecadado pela população do município. A seguir, é apresentada a fórmula utilizada para o cálculo.

O PIB representa a soma (em valores monetários) de todos os bens e serviços finais produzidos no município, e é de relevante importância para os gestores públicos, enquanto instrumento auxiliar de planejamento municipal, bem como no processo de desenvolvimento.

Além destas, foram selecionadas, a partir da construção do referencial teórico, duas outras variáveis classificadas como de controle: a população de cada município e o ano dos dados. O controle destas variáveis é importante para captar mudanças no decorrer do tempo e o efeito que a população pode ter sobre o índice. No Quadro 4 estão descritas e classificadas as variáveis. 
Quadro 4 - Descrição e classificação das variáveis

\begin{tabular}{|l|l|l|}
\hline Classificaçáo & \multicolumn{1}{|c|}{ Variável } & \multicolumn{1}{c|}{ Descriçáo } \\
\hline Dependente & IDESE & $\begin{array}{l}\text { Índice calculado pela FEE que mede o desenvolvimento } \\
\text { socioeconômico dos municípios gaúchos. É expresso de 0 a } \\
1, \text { sendo considerados melhores os municípios que possuem } \\
\text { esse índice mais próximos de 1. }\end{array}$ \\
\hline \multirow{3}{*}{ Independente } & $\begin{array}{l}\text { Arrecadação per } \\
\text { capita (LOG) }\end{array}$ & $\begin{array}{l}\text { Índice obtido dividindo-se o total arrecadado pela população } \\
\text { do município. Demonstra quanto poderia ser gasto com } \\
\text { cada habitante do valor total arrecadado. }\end{array}$ \\
\cline { 2 - 4 } Controle & PIB (LOG) & $\begin{array}{l}\text { Representa a soma (em valores monetários) de todos os bens } \\
\text { e serviços finais produzidos no município. }\end{array}$ \\
\hline & População & $\begin{array}{l}\text { O número total de habitantes de cada município de acordo } \\
\text { com dados da FEE. Será utilizado para calcular a Arrecadaçáo } \\
\text { per capita. }\end{array}$ \\
\cline { 2 - 3 } & Ano & O ano dos dados utilizados. \\
\hline
\end{tabular}

Fonte: Elaboração própria (2016).

\subsection{Procedimentos Econométricos, Definiçáo do Modelo e das Variáveis de Análise}

Em razão da característica dos dados, optou-se por trabalhar com a técnica de análise de regressão linear múltipla, pelo método dos mínimos quadrados ordinários com dados em painel. Para a operacionalização, utilizou-se o software Eviews7.

Inicialmente, analisou-se a colinearidade das variáveis através da Matriz de Correlação de Pearson no modelo da pesquisa. Para Marchiori (2015), a colinearidade é configurada, quando índices elevados de correlaçóes são encontrados, indicando similaridade entre as variáveis explicativas que se potencializam e prejudicam as estimativas dos betas do modelo.

Os resultados das combinaçóes, em sua maioria, foram inferiores a 0,60 , o que indica não haver forte correlação entre as variáveis, conforme a premissa de Callegari-Jacques (2003). Apenas em dois resultados obtiveram-se combinaçóes maiores que 0,60; entre a Arrecadação per capita e a População $(-0,661130)$ e entre a População e o PIB $(0,930889)$.

Com isso, optou-se pela exclusão da variável população do modelo, uma vez que mostra alta correspondência com a arrecadação e com o PIB, além de não representar uma variável de cunho econômico, que é o principal interesse desse estudo.

Após, apurou-se o teste de Variance Inflation Factors (VIF) a fim de verificar a multicolinearidade entre as variáveis. Cabe destacar que a multicolinearidade é configurada, quando variáveis combinadas possuem elevada correlação com uma das variáveis, da mesma forma que, na colinearidade, os betas do modelo serão imprecisos na incidência de multicolineariedade (MARCHIORI, 2015). Segundo Baum (2006), a interpretação do teste VIF pode ser feita levando em consideração que valores acima de 10 evidenciam 
indícios de multicolinearidade. Nos resultados do teste não houve, em nenhum dos casos, valores superiores a 10, o que indica que não há multicolinearidade entre as variáveis.

Há diferentes modelos de dados em painel. A distinção básica entre eles está atrelada a existência de efeitos fixos (EF) ou aleatórios (EA). Conforme Wooldridge (2006), o primeiro a sugerir um teste para escolha entre EA e EF foi Hausman em 1978. Este teste consiste na verificação da existência de correlação entre \'it e x'it, assumindo que os erros idiossincráticos e as variáveis explicativas não são correlacionados ao longo do tempo, ou seja, a hipótese nula do teste é a opção pelo modelo EA. Foi aplicado o teste de Hausman na equação e os resultados indicaram para a utilizaçáo de EA.

Observou-se também a heterocedasticidade dos resíduos dos modelos $\left(\mathrm{H}_{0}\right.$ : Homocedasticidade; $\mathrm{H}_{1}$ : Heterocedasticidade) por meio do Teste White. $\mathrm{O}$ modelo apresentado na pesquisa apresentou heterocedasticidade, que pode ser definida como uma forte dispersão dos dados em torno da reta ou uma dispersão dos dados perante um modelo econométrico regredido. Com isso, utilizou-se a matriz de White Cross-Section no modelo para tratamento dos dados.

Verificou-se ainda a autocorrelação por meio do teste de Breusch-Goodfrey $\left(\mathrm{H}_{0}\right.$ : Não há autocorrelação; $\mathrm{H}_{1}$ : Há autocorrelação) e pelo valor de DW - Durbin-Watson. Os dados encontrados no teste apresentaram autocorrelação. A tentativa de estimar por quase diferenças, para corrigir o problema de autocorrelação, piorou os resultados da estimação. No modelo final, o teste de Durbin-Watson ficou, marginalmente, na zona de indefinição.

Ao analisar a distribuição dos erros da análise de regressão pode-se perceber que estes não são distribuídos normalmente. A seguir é apresentado o modelo aplicado para teste das hipóteses da pesquisa.

O modelo é composto pela variável dependente IDESE - que representa o índice obtido pelos municípios - e as independentes Arrecadação per capita (LOG) - que representa a receita para cada habitante dos municípios gaúchos em estudo - e PIB (LOG) - que representa o produto interno bruto do município. A variável ANO é de controle. A informação "i" representa o município e o " $\mathrm{t}$ " o tempo de cada informação. $\mathrm{O} \alpha$ são interceptos específicos para cada unidade que afetam a relação da variável dependente e as demais, e o representa o erro residual da regressão.

No Quadro5, apresenta-se o sinal esperado dos betas das variáveis independentes, conforme os pressupostos apresentados no referencial teórico desta pesquisa.

Quadro 5 - Sinais esperados para as Variáveis Independentes

\begin{tabular}{|c|c|}
\hline Variável & Sinal Esperado \\
\hline Arrecadação & $\beta>0$ \\
\hline PIB & $\beta>0$ \\
\hline
\end{tabular}

Fonte: Elaboração própria (2016). 


\section{RESULTADOS E DISCUSSÓES}

\subsection{Análise Descritiva}

Primeiramente, realizou-se a análise descritiva da variável dependente (IDESE) e das independentes (ARRECpc e PIB). Consideraram-se para a análise descritiva as medidas de média, mediana, máximo, mínimo e desvio padrão. A Tabela 1 apresenta um resumo estatístico das variáveis, afim de que se avaliem suas magnitudes e dispersóes.

Tabela 1 - Análise descritiva das variáveis de estudo

\begin{tabular}{c|c|c|c|c|c|c|c}
\hline $\begin{array}{c}\text { Classificaçáo } \\
\text { da Variável }\end{array}$ & Variável & $\begin{array}{c}\text { Tipo de } \\
\text { Variável }\end{array}$ & Média & Mediana & Máximo & Mínimo & $\begin{array}{c}\text { Desvio } \\
\text { Padráo }\end{array}$ \\
\hline Dependente & IDESE & Contínua & 0,705 & 0,708 & 0,882 & 0,506 & 0,062 \\
\hline Independente & ARRECpc & Contínua & $2.734,24$ & $2.438,33$ & $12.029,51$ & 727,84 & $1.227,71$ \\
\hline Independente & PIB & Contínua & $538.266,87$ & $98.704,76$ & $57.379 .336,78$ & $15.626,83$ & $2.520 .591,13$ \\
\hline
\end{tabular}

Fonte: Elaboração própria (2016).

De acordo com a Tabela 1 , em relação à variável dependente IDESE, obtém-se a média de 0,705 , indicando que a maioria dos municípios possui um IDESE médio, ou seja, entre 0,500 e 0,799. A mediana de 0,708, próxima da média, reforça o indicativo de que são poucos os municípios com IDESE alto, mesmo a maior parte dos dados estando acima do ponto médio. Os valores não possuem grande variabilidade, visto que o desvio padrão que é de 0,062 representa apenas $8,79 \%$ do valor da média. O município de Carlos Barbosa sustenta o indicador máximo de 0,882 no ano de 2013 e o município de Jaquirana o indicador mínimo de 0,506 em 2009.

A variável independente arrecadação per capita (ARRECpc) foi obtida a partir da divisão da arrecadação total dos municípios pela população (POP) destes, revelando grande variação em sua distribuição de acordo com o desvio padrão obtido, que é de R $\$ 1.227,71$ e representa $44,90 \%$ da média. A média de arrecadação per capita é de $\mathrm{R} \$ 2.734,24$ por habitante, bem abaixo da máxima, obtida pelo município de Alto Alegre em 2013, no valor de $\mathrm{R} \$ 12.029,51$ por habitante. O menor valor foi obtido no município de Viamão em 2009 , que registrou apenas $\mathrm{R} \$ 727,84$ por habitante. A mediana de $\mathrm{R} \$ 2.438,33$, abaixo do valor médio, indica que a maioria dos municípios tem arrecadado, por habitante, um valor abaixo da média.

O PIB também possui grande variação em sua distribuição. $\mathrm{O}$ desvio padrão de $\mathrm{R} \$$ 2.520.591,13 deve-se à grande amplitude entre os valores máximos e mínimos. A média é de $\mathrm{R} \$ 538.266,87$ e a mediana de $\mathrm{R} \$ 98.704,76$, indicando que a maior parte dos municípios possui um PIB abaixo da média. Porto Alegre revelou-se o município de maior PIB em 2013, no valor de $\mathrm{R} \$ 57.379 .336,78$. Já o menor foi registrado em Benjamin Constant do Sul, de R\$15.626,83 no ano de 2012.

Analisando as 2.480 observaçóes, têm-se os municípios com os melhores e piores resultados do estado no período na Tabela 2 . 
Tabela 2 - Os municípios com os melhores e piores resultados do estudo

\begin{tabular}{l|c|c|c|c}
\hline \multicolumn{1}{c|}{ Município } & Ano & Arrecadaçáo per capita & IDESE & Índice IDESE \\
\hline Carlos Barbosa & 2011 & $\mathrm{R} \$ 2.065,40$ & 0,861 & Alto \\
\hline Jaquirana & 2010 & $\mathrm{R} \$ 2.294,00$ & 0,510 & Médio \\
\hline Viamão & 2009 & $\mathrm{R} \$ 727,84$ & 0,582 & Médio \\
\hline Alto Alegre & 2013 & $\mathrm{R} \$ 12.029,51$ & 0,797 & Médio \\
\hline
\end{tabular}

Fonte: Elaboração própria (2016).

O município de Carlos Barbosa teve arrecadaçáo per capita de R \$2.065,40 no ano de 2011 e IDESE de 0,861, o melhor do estado naquele ano. Em contrapartida, o município de Jaquirana, com arrecadaçáo per capita de $\mathrm{R} \$ 2.294,00$ (valor maior que o de Carlos Barbosa) no ano de 2010 apresenta o IDESE de 0,510, o pior do estado naquele ano.

O município com a menor arrecadação per capita do estudo foi Viamáo e, consequentemente, este município apresenta índices IDESE de médio desenvolvimento (entre 0,500 e 0,799 ) nos cinco anos estudados. Por sua vez, o município com a maior arrecadação per capita, Alto Alegre, também teve índice IDESE médio em todos os anos analisados.

\subsection{Análise de Regressáo}

$\mathrm{Na}$ Tabela 3 são apresentados os resultados do modelo de regressão, conforme investigação do objetivo da pesquisa.

Tabela 3 - Análises Modelo

\begin{tabular}{|c|c|c|c|c|c|}
\hline Classificação & Variáveis & Coeficiente & Erro Padrão & t-Estatístico & Probabilidade \\
\hline \multirow{4}{*}{ 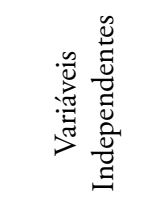 } & & & & & \\
\hline & LOG_ARREC $p c$ & 0.111212 & 0.011630 & 9.562879 & $0.0000^{* * *}$ \\
\hline & LOG_PIB & 0.065705 & 0.007911 & 8.305100 & $0.0000^{* * *}$ \\
\hline & & & & & \\
\hline \multirow{5}{*}{ 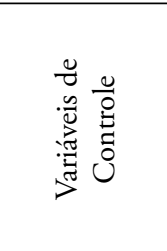 } & NUM2010 & -0.013422 & 0.000879 & -15.26354 & $0.0000^{* * *}$ \\
\hline & NUM2011 & -0.008595 & 0.001157 & -7.430040 & $0.0000^{* * *}$ \\
\hline & NUM2012 & -0.007578 & 0.001632 & -4.642655 & $0.0000^{* * *}$ \\
\hline & NUM2013 & 0.005626 & 0.001534 & 3.666479 & $0.0003^{* * *}$ \\
\hline & $\mathrm{C}$ & -0.005647 & 0.027764 & -0.203378 & 0.8389 \\
\hline
\end{tabular}




\begin{tabular}{|c|c|c|c|c|c|}
\hline Classificação & Variáveis & Coeficiente & Erro Padrão & t-Estatístico & Probabilidade \\
\hline \multirow{8}{*}{ 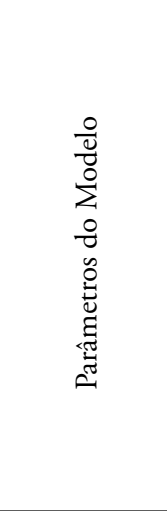 } & $\begin{array}{l}\text { Variável } \\
\text { Dependente }\end{array}$ & IDESE & & & \\
\hline & $\mathrm{N}$ & 2.480 & & & \\
\hline & Efeito Ano & $S$ & & & \\
\hline & $\mathrm{EF} / \mathrm{EA}$ & EA & & & \\
\hline & Hausman Test & $0.000^{* * *}$ & & & \\
\hline & $\begin{array}{l}\text { Adjusted } \\
\text { R-squared }\end{array}$ & 0.591538 & & & \\
\hline & $\begin{array}{l}\text { Durbin-Watson } \\
\text { stat }\end{array}$ & 1.384318 & & & \\
\hline & Prob(F-statistic) & 0.00000 & & & \\
\hline
\end{tabular}

$\mathrm{Na}$ coluna são apresentados os Betas (coeficientes); o erro padrão, o t-Estatístico e as significâncias das variáveis a ${ }^{* * *} 1 \% ;{ }^{* *} 5 \%$ e ${ }^{*} 10 \%$. Também se apresentam os parâmetros gerais do modelo. As variáveis analisadas são: IDESE; LOG da arrecadaçáo per capita - LOG_ARREC $p c$;LOG do PIB-LOG_PIB; a variação dos indicadores ao longo dos anos através das variáveis -NUM2010, NUM2011, NUM2012, NUM2013.

Fonte: Elaboração própria.

Nota-se que o coeficiente da variável independente LOG_ARRECpc é positivo em 0.111212 e, estatisticamente significante a $1 \%$. Isso indica que os municípios que mais arrecadam conseguem transformar essa maior arrecadação em uma melhor qualidade de vida a seus cidadãos. Essa relação indica que para cada $1 \%$ de aumento na arrecadação per capita, tem-se um aumento de 0,11\% no IDESE do município.

As constataçóes dos autores Silva et al. (2013) e Fernandes (2017) apresentados no capítulo 2 , de que é positiva a relação entre a arrecadação municipal e os índices de desenvolvimento sociais confirmam-se neste estudo.

Logo, verifica-se que a arrecadação tem a função de servir a máquina pública, a fim de fomentar os serviços sociais. Essa relação positiva demonstra a efetividade da carga tributária imposta às pessoas como forma de retorno social aos cidadãos, muito embora essa relação poderia ser mais efetiva que $0,11 \%$ de aumento no IDESE para cada $1 \%$ de aumento na arrecadação, já que conforme Fonseca e Fagnani (2013), o desenvolvimento social deve ser um dos principais objetivos do Estado.

A relação positiva entre a arrecadação e o IDESE explica-se, principalmente, pelo indicativo da boa gestão dos recursos públicos pelos gestores municipais. Percebe-se que os municípios que mais arrecadam vêm transferindo parte desses recursos em prol da população, seja por meio da saúde, educação e/ou lazer. A priorização de investimentos nas áreas da saúde, educação e lazer, por parte dos governantes, faz com que os cidadãos logrem uma melhor qualidade de vida e, consequentemente, o município tenha melhor resultado no IDESE.

Analisando a outra variável independente, LOG_PIB, percebe-se também um coeficiente positivo e estatisticamente significante, indicando que quanto maior o PIB, maior também será o IDESE. Essa relação indica que, para cada $1 \%$ de aumento no PIB, tem-se um aumento de 0,06\% no IDESE do município. 
As constataçóes dos autores Avelar, Garcia e Santos (2012) e Fernandes (2017) apresentadas no capítulo 2, de que é positiva a relaçáo entre o crescimento econômico e os indicadores de desenvolvimento sociais, confirmam-se neste estudo.

A relação positiva entre o PIB e o IDESE indica que o desempenho econômico influencia positivamente o desempenho social, deste modo, pode-se inferir que quanto mais bens e serviços forem produzidos em determinado município, maior será a renda da população e, consequentemente, maior será o acesso destes cidadãos à educação, saúde e lazer, melhorando a qualidade de vida das pessoas.

Neste sentido, o resultado desta pesquisa indica que um aumento no PIB é capaz de gerar melhora no desenvolvimento econômico municipal, conforme Siedenberg (2006), trazendo benefícios na qualidade de vida da população. De acordo com Avelar, Garcia e Santos (2012) o Brasil é o próprio exemplo do poder do crescimento econômico no desenvolvimento social, referenciado o período de crescimento da economia de 2000 a 2010 com a melhora dos indicadores sociais nesse período.

O estudo indica, portanto, a influência do PIB e da arrecadação municipal sobre o IDESE, embora a influência exercida pelo PIB sobre o IDESE seja menor que o impacto da arrecadaçáo municipal sobre o indicador. Isso sugere que a riqueza, quando conduzida pela gestão pública, tem maior efeito na qualidade de vida e bem-estar dos cidadãos do que quando particionada com a iniciativa privada. Ainda, os resultados encontrados com o estudo evidenciam a importância de os municípios buscarem maiores PIBs e aumentos efetivos na arrecadação, tendo em vista a consequência gerada com o aumento da qualidade de vida de seus cidadãos.

Contudo, conclui-se que tanto a arrecadação municipal como o PIB influenciam diretamente no resultado do IDESE, e, portanto, ambos devem estar no enfoque das políticas públicas, como caminho para alcançar aquela que é função principal do estado, atender as necessidades da populaçâo proporcionando a ela uma qualidade de vida cada vez melhor.

\section{CONSIDERAÇÓES FINAIS}

O presente estudo teve por objetivo analisar se o nível de arrecadaçáo e o PIB interferem no Índice de Desenvolvimento Socioeconômico em municípios do Rio Grande do Sul. Foram considerados 496 municípios gaúchos e 2.480 observaçóes no período entre 2009 e 2013. Para atendimento desse objetivo, foi aplicada, no método, a técnica de análise de regressão linear múltipla pelo método dos mínimos quadrados ordinários com dados em painel.

Os resultados da pesquisa foram analisados sob duas óticas. $\mathrm{Na}$ análise descritiva, consideraram-se as medidas de média, mediana, máximo, mínimo e desvio padrão, a fim de verificar a distribuiçấo dos dados. A média do IDESE no período analisado para os municípios do Rio Grande do Sul é de 0,705, ou seja, um índice IDESE médio. O município que teve o maior índice foi Carlos Barbosa, 0,882 no ano de 2013; já o município com o pior índice no período analisado foi Jaquirana, 0,506 no ano de 2009. 
$\mathrm{Na}$ análise do modelo econométrico, observou-se que os níveis de arrecadação municipal são capazes de influenciar positivamente o IDESE. Ou seja, verificou-se que quanto maior a arrecadação de um município, consequentemente, maior será o seu índice IDESE. O resultado encontrado no estudo indica que, para cada $1 \%$ de aumento na arrecadação per capita, tem-se um aumento de $0,11 \%$ no IDESE do município.

A relação positiva entre a arrecadação e o IDESE é explicada, principalmente, pela boa gestáo dos recursos públicos pelos gestores municipais. Percebe-se que os municípios que mais arrecadam vêm transferindo parte desses recursos em prol da população, através da saúde, educação e lazer.

Também foi encontrado um coeficiente positivo entre a outra variável independente, o PIB, sobre o IDESE, o que indica que, quanto maior o PIB, maior também será o IDESE. $\mathrm{O}$ resultado indica que para cada $1 \%$ de aumento no PIB, tem-se um aumento de $0,06 \%$ no IDESE do município.

A relação positiva entre o PIB e o IDESE ocorre pelo fato de que quanto mais bens e serviços forem produzidos em um determinado município gerando maior desempenho econômico, maior será a renda dos cidadãos e, consequentemente, maior será o acesso destes à educação, saúde e lazer, melhorando a qualidade de vida dos mesmos. Com isso percebe-se que não é possível desvincular o crescimento econômico da melhora da qualidade de vida das pessoas.

Uma importante reflexão a partir desse estudo é o papel do Estado, que tem como uma das atividades principais realizar esse equilíbrio social entre os municípios com mais recursos e aqueles mais pobres. Contudo, ao coletar e analisar os dados propostos pelo estudo ficou claro que esse papel não vem sendo cumprido, havendo grande desigualdade na distribuição de renda entre os municípios e consequente impacto na qualidade de vida das pessoas. Essa pesquisa, entâo, contribui também para que possa ser questionado e repensado o papel do Estado em relação às atividades básicas e essenciais que o mesmo se propôe perante aos cidadáos.

Para pesquisas futuras, sugere-se realizar esse estudo com dados atualizados, quando da divulgação do IDESE 2014-2015, bem como realizar essa análise nos demais estados brasileiros, a fim de comparar os resultados obtidos.

\section{REFERÊNCIAS}

ALMEIDA, H. A. Análise da Eficiência da Tributaçáo em Relaçáo ao Retorno do

Bem-estar à Sociedade. 2014. 53 p. Monografia (Graduação em Ciências Econômicas) Instituto de Ciências Econômicas, Administrativas e Contábeis - Universidade Federal do Rio Grande, Rio Grande, RS.

AVELAR, Paulo R.; GARCIA, Esther G.; SANTOS, Agnaldo C. Crescimento

Econômico e Desenvolvimento Social no Brasil. 2012. Disponível em: <http://www. unescap.org/unis/press/G_05_00.htm>. Acesso em: 10 ago. 2017.

BAUM, C. F. An introduction to modern econometrics using stata. Stata Press. 2006. 
BRASIL. Constituição da República Federativa do Brasil. 1988.

BRASIL. Lei Complementar no 116, de 31 de julho de 2003.

BRASIL. Lei no 10.028 , de 19 de outubro de 2000 .

BRASIL. Lei no 4.320, de 17 de março de 1964.

BRASIL. Lei no 5.172, de 25 de outubro de 1966.

CALLEGARI-JACQUES, S. M. Bioestatística: princípios e aplicações. Porto Alegre: Artmed, 2003.

CARLEY, Michael. Indicadores sociais: teoria e prática. Rio de Janeiro, Zahar, 1985.

FEE. FUNDAÇÃO DE ECONOMIA E ESTATÍSTICA. Disponível em: <http://www. fee.rs.gov.br/>. Acesso em: 20 ago. 2016.

FEIJÓ, Carmem A. Para entender a conjuntura econômica. Curitiba, PR, Manole, 2011.

FERNANDES, Charles Menis. Desempenho tributário e índice de desenvolvimento econômico-social em municípios mineiros. Rio Paranaíba, 2017. 31f. Trabalho de Conclusão de Curso (Curso e Ciências Contábeis) UFV, 2017.

FONSECA, Ana; FAGNANI, Eduardo (orgs.). Política social, desenvolvimento e Cidadania. Economia, distribuição de renda e mercado de trabalho. São Paulo: Fundação Perseu Abramo, 2013.

GALLO, Mauro F; PEREIRA, Carlos A.; CORRAR, Luis J.; REIS, Luciano G.; A Distribuiçáo da Arrecadação do ICMS no Estado do Pará e o Comportamento do IDH-M. UNOPAR Cient., Ciênc. Juríd. Empres., Londrina, v. 13, n. 1, p. 123-132, Mar. 2012.

KASZNAR, Istvan. Produto Interno Bruto dos Municipios. Revista Cientifica e Tecnógica. N59, 2013.

KEINERT, R. C. Prefácio. In: JANNUZZI, P. M. Indicadores Sociais no Brasil. Campinas, Editora Alínea, 2001.

KOHAMA, Heilio. Contabilidade pública: teoria e prática. 14. ed. São Paulo: Atlas, 2014.

MARCHIORI, Felipe William. O Efeito dos Níveis Diferenciados de Governança Corporativa da Bovespa na Criação de Valor e no Desempenho operacionaldas 
Companhias Brasileiras. Casca, 2015. 45f. Trabalho de Conclusão de Curso (Curso e Ciências Contábeis) UPF, 2015.

OLIVEIRA, Luis Martins de; CHIEREGATO, Renato; PEREZ, José Hernandez. Sistema Tributário Nacional. In: Manual de Contabilidade Tributária: textos e testes com respostas. 13. ed. São Paulo: Atlas, 2014. p. 3- 9.

PAVARINA, Paula Regina de Jesus Pinseta. Desenvolvimento, crescimento econômico e o capital social no estado de Sáo Paulo. Tese (Doutorado), Escola Superior de Agricultura Luiz de Queiroz - ESALQ. Piracicaba, 2003.

SLOMSKI, Valmor. A Contabilidade Gerencial: O Estado e a Sociedade. In: Manual de Contabilidade Pública. 2. ed. Sáo Paulo: Atlas, 2003. p. 303-358.

SILVA, Lino Martins da. Orçamento Público. In: Contabilidade Governamental. 9. ed. São Paulo: Atlas, 2011. p. 172-278.

SILVA, L. L.; SILVEIRA, S. F. R.; COSTA, T. M. T.; FARONI, W.; FERREIRA, M. A. M. A influência do desempenho tributário e gestão fiscal no Índice Firjan de Desenvolvimento (IFDM) dos municípios de Minas Gerais. Revista de Ciências Humanas, v. 13, n. 1, p. 199-219, jan./jun., 2013.

SIEDENBERG, D. R. Dicionário do Desenvolvimento Regional. Santa Cruz: Edunisc, 2006.

TCE-RS. TRIBUNAL DE CONTAS DO ESTADO DO RIO GRANDE DO SUL. Disponível em: <http://www.tce.rs.gov.br>. Acesso em: 2 set. 2016.

WOOLDRIDGE, J. M. Introdução à Econometria uma Abordagem Moderna. São Paulo: Thomson Pioneira, 2006. 